\title{
An ANP-Based Network to Measure the Impact of Lean Production on Organisational Performance
}

\author{
José Luis Ruano PéreziD, Raúl Rodríguez-Rodríguez (D), Juan-José Alfaro-Saiz(D), María-José Verdecho(iD \\ Universitat Politècnica de València (Spain) \\ joruape@etsid.upv.es,raurodro@cigip.upv.es,jalfaro@cigip.upv.es,mverdecho@cigip.upv.es
}

Received: November 2017

Accepted: December 2017

\begin{abstract}
:
Purpose: The main objective of this research is to design a decision-making network, based on the Analytic Network Process (ANP) technique (Saaty, 1996), which will include the main elements to take into account when stating the effect that the application of LP techniques has got on the performance of an organisation, measured this through a Performance Measurement System (PMS).
\end{abstract}

Design/methodology/approach: The authors have carried out a scientific literature search to state what the main LP techniques are -and how to group them into different clusters- and have then applied the ANP, its first phase, in order to design the decisional network.

Findings: There is a gap in the literature when trying to identify and quantify to what extent the implementation of LP techniques affects to organisational performance. The ANP is an appropriate technique to do so due to the need of gathering and quantifying experts' opinions.

Originality/value: The designed ANP-based network to measure the impact of LP over organisational performance is a novel approach. This paper justifies its usage and paves the way to implement the rest of the ANP phases in future research work.

Keywords: lean production, organisational performance, analytic network process

\section{Introduction}

Lean Production (LP) means a set of techniques widely used not only in industry but also in-service organisations like hospitals. LP has been regularly used, in greater or lower degree, in many companies in the last 40 years, as their proper application usually results into more efficient processes and, extensively, organisations. It can be said that LP was born in the context of the automobile industry in Japan, taking as initial point Ford's manufacturing method. Then, LP is an evolution of such a system, as it combines automated manufacturing with small batches manufacturing. Then, the manufacturing of these small batches together with a fast organisation avoids both excessive and obsolete stocks as well as low quality levels.

In general, LP is a market-oriented system focused on meeting customer's demands. With a just in time strategy what it is sought is to provide what the customer demands, in the way it is expected, with the adequate quality level and delivering it when it is demanded. All this having manufactured the product with the minimum resources, avoiding waste, waiting times and high stock levels. 
There are many LP techniques such as the following:

- $5 \mathrm{~S}$ are five basic principles, meaning: seiri (methodical arrangement), seiton (order), seiketsu (state of cleaning), seiso (cleaning) and shisuke (discipline). In order to accomplish their more efficient implementation, it is necessary an appropriate training on the adequate methods to apply to the working area.

- Total Productive Maintenance (TPM) is the total or final maintenance management. The question here is: How is it possible to achieve zero level of breaking downs? The, the five breaking down phases of equipment are analysed: latent minor defects, apparent minor defects, process execution below the expected levels, intermittent stops and stops due to breaking downs.

- Total Quality Management (TQM) is the total quality management. There are many techniques within TQM but the main idea is that delivering quality products/services is the most important regarding the production process independently of the production process employed.

- $\quad$ Single Minute Exchange Die (SMED) is a technique that aims that the tool set up time can be expressed with a single digit (less than 10 minutes). Its correct application facilitates a continuous production flow, decreasing cycle times and, extensively, increasing production rates with lower stock levels.

There are more LP techniques such as Just in Time, standardisation, Poka-yoke, Baka-yoke, Heijunka, Jidoka, Kanban among others and an organisation should analyse what of these are better for them and the degree of relationships between them.

Hence, it is widely agreed that the application of LP techniques impacts over organisational performance. The main question to be answered is: To what extent? In other words, an organisation invests resources on applying LP techniques and it wants to know what the payback is.

In order to answer this question, this paper analyses next the main scientific literature that deals with LP and performance measurement in order to demonstrate this research gap. It then moves into identifying appropriate techniques that could be used to effectively link LP and performance management, at all decision-making levels. It then selects one of these techniques, the Analytic Network Process and design a decisional network following the guidelines of such a technique. Finally, the main conclusions and future research work are highlighted.

\section{Literature Review}

\subsection{Performance Measurement Systems (PMS)}

Since the 1990s, the process of measuring organisational performance has adopted a balanced approach. The wellknown Balanced Scorecard (Kaplan \& Norton, 1992) contributed to focus not only on financial but also on other organisational dimensions when measuring performance. These others dimensions or perspectives (Customers, Internal Processes, Learning \& Growth) gave the opportunity to make better analyses and conducted to better decisions. There are many other PMS such as the Performance Pyramid (Lynch \& Cross, 1991), Neely's Performance Prism (Neely, Adams \& Kennerley, 2002), among others; but from all these the most extended and used by both researchers and practitioners is the Balanced Scorecard due to its simplicity and usability.

\subsection{PMS and LP}

In the last years, there have been many publications regarding how to measure LP in organisations. However, these works focus mainly on KPIs that measure LP techniques efficiency. Further, when looking at publications that deal with combining both LP and Performance Measurement Systems, the results are reduced in number. In this sense, Lee and Yang (2011) propose the application of LP performance measures integrated with the four Balanced Scorecard perspectives. On the other hand, Govindan, Azevedo, Carvalho and Cruz-Machado (2015) proposes an approach to link innovation measurement and LP but it does not cover the whole strategic balanced approach. Bashin (2012) set up a study of how large organisations have benefit from having applied LP techniques but without quantifying the link between performance and implementation of LP techniques. Seyedhosseini, Taleghani, Bakhsha and Partoviet (2011) carried out a study to extract some leanness criteria employing a Balanced Scorecard. 
Finally, Lee, Park and Lim (2013) used a Balanced Scorecard approach for the evaluation of Software as a Service, where some LP performance measures were included.

Hence, it is possible to affirm that there is a gap in the literature when trying to identify and quantify to what extent the implementation of LP techniques affects to organisational performance. This may be due to the fact that this is not a simple action, as it is difficult to allocate how and to what extent the application of a LP technique (operativetactic one) affects to the achievement of organisational strategic objectives. Traditional quantitative techniques such as statistical techniques difficult to be applied here, as these techniques usually get as an input historical data. Then, a technique that can deal with this problem should be able to gather the opinion of experts that could establish the link between the application of LP techniques and the achievement of organisational performance. Such a technique is presented in the next point: The Analytic Network Process.

\section{Analytic Network Process}

Saaty (1996) created the Analytic Network Process (ANP) technique and it is a well-known technique to be applied in decision-making problems with multiple alternatives and criteria. In the last years, it has been applied to different sectors and problematic such as: Project Management (Aragonés-Beltrán, García-Melón \& Montesinos-Varela, 2017), selection of suppliers (Asadabadi, 2017), etc. Further, regarding how to evaluate to what extent certain business practices are influencing over organisational performance, it is necessary to highlight the following works: Verdecho, Alfaro-Saiz, Rodriguez-Rodriguez and Ortiz-Bas (2012) developed a methodology to link how and to what extent collaborative factors and practices were affecting to organisational performance. In the centre of this methodology was the ANP as mathematical tool to collect and transform expert's opinions about this matter. Additionally, Boj, Rodriguez-Rodriguez and Alfaro-Saiz (2014) applied ANP to link intangible assets and organisational performance. It is important to point out that in these both researches there were not specific KPIs that had collected data regarding how either intellectual capital or collaborative actions were affecting to organisational performance. This absence of historical/real data made necessary the usage of a subjective technique such as ANP. In this sense, this is the same scenario when trying to link and quantify how the application of LP techniques is affecting to organisational performance.

The ANP comprises six main phases:

1. Representation of the decision problem as a network where both the criteria and the alternatives are classified into clusters, establishing relationships (or dependences) not only inter-clusters but also intraclusters.

2. Pairwise comparison between elements and eigenvectors. A group of experts answers about how important a certain element, compared to another one, is when aiming to reach a third one.

3. Unweighted Supermatrix, as a result of the eigenvectors from last phase.

4. Pairwise comparison. This comparison is made between clusters, with the main of identifying the main cause-effect relationships between them (similar to phase 2 with elements).

5. Weighted Supermatrix, as a result of multiplying the unweighted one by the clusters weights.

6. Composition of the Limit Supermatrix, as a result of raising the Weighted Supermatrix to the n-power till it gets stabilised. This Limit Supermatrix has got the global priorities of all the elements considered.

After having obtained the Limit Supermatrix, it is possible to carry out graphic analyses of the achieved results, which makes simpler the interpretation of the analytic results, facilitating to decision-makers a global vision. Figure 1 illustrates this, as it shows:

- The relationships between the inputs (above Figure 1), regarding intellectual capital, and how these influence to the achievement of the organisational strategic objectives of the organisation (in the middle of Figure 1) and vice versa (as the relationships are bidirectional ones).

- The relationships between the organisational strategic objectives of the organisation (in the middle of Figure 1) and the outputs to be created, in terms of intellectual capital, when achieving the strategic objectives and vice versa (as the relationships are bidirectional ones). 
Further, the ANP facilitates to carry out what-if analyses in terms of sensibility analysis. Then, from the initial obtained results, decision-makers may want to check what would happen if changing the weight of some of the elements. For instance, it would be possible to analyse what would happens if some important cause elements (imagine in this case, for instance, augmenting investment on SMED and Poka-yoke techniques) varied their values and the impact over some important effect elements (imagine for instance Financial Strategic Objectives).

To sum up, it is possible to affirm that ANP is a suitable and convenient technique to apply when aiming to quantify what the impact over organisational performance the implementation of LP techniques has got.

In this paper, it is shown the design and development of phase 1, Representation of the decision problem as a network, which is next developed.

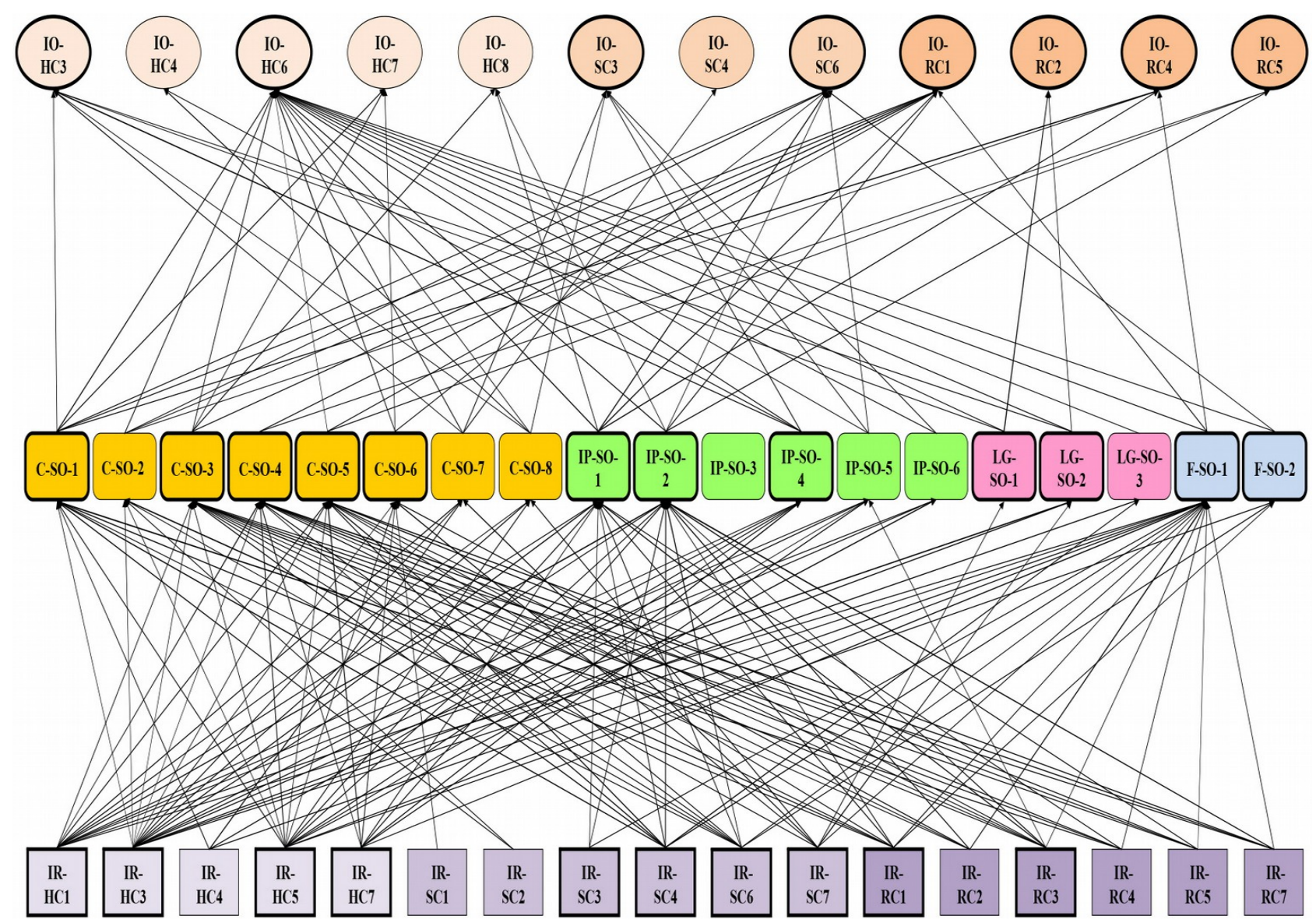

Figure 1. Graphic of global deployment of the intangible assets (Boj et al., 2014)

\section{ANP-Based Network to Measure the Impact of Lean Production on Organisational Performance}

As pointed out in the last point, here it is now not only presented the designed ANP-based network to link and measure the impact of LP on organisational performance but also developed.

Initially, the idea was to link how the election, definition and implementation of some LP techniques were affecting over organisational performance. To this end, a cluster of Inputs was defined, being constituted by LP techniques. On the other hand, organisational performance was represented through a cluster called Performance Measurement Systems. The idea is that the relationships between these two clusters are bidirectional. In other words, the implementation of LP techniques will have an impact on organisational performance elements, strategic objectives and KPIs, and vice versa; the achievement of organisational performance elements will produce an impact over the acquisition and implementation of LP techniques, which may be the same ones that are already in use and/or new ones. 
Further, this initial idea lead to consider not only the inputs but also the outputs that are produced as a consequence of the design and implementation of the inputs, creating another cluster: The Outputs cluster. In other words, some specific inputs (LP techniques) will lead not only to the achievement, in higher or lower degree, of the organisational performance but will also produce some outputs, which will be not gathered within these organisational performances per se. It is important to point out that such a relationship is not bi-directional, as it goes from inputs (cause cluster) to outputs (effect cluster). Additionally, the creation of these outputs will be also fostered by the achievement, to some extent, of the organisational performance and vice versa; the creation of these outputs will have an impact over organisational performance.

Finally, it was agreed that the discussion needed to take into account the stakeholders' needs, and a Stakeholders' needs cluster was introduced into the decisional network. Since Stakeholders' needs is something that is affecting to the development of the whole organisation, this cluster maintains bi-directional relationships with all the other three clusters.

Figure 2 illustrates these four clusters and inter-cluster relationships. It is necessary to point out that the intraclusters relationships also take place, as elements from common clusters may keep important relationship and the ANP technique has got the capability to identify and quantify them too.

The main elements of these four clusters are next presented.

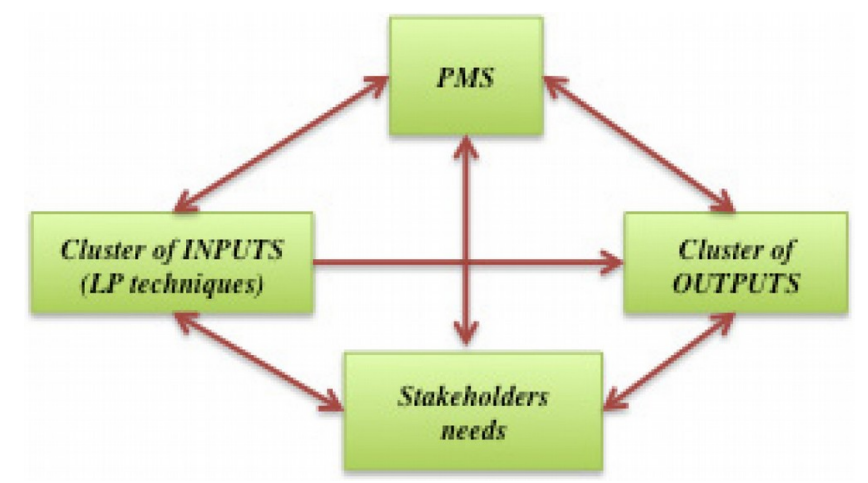

Figure 2. ANP-based network to measure the impact of LP on organisational performance

\subsection{Cluster of Inputs}

This cluster is constituted by the main LP techniques used in both industry and service organisations:

- Just in Time

- Kanban

- $5 \mathrm{~S}$

- TPM

- TQM

- Poka-joke

- Jidoka

- SMED

- Training of personnel

- Standardisation

- Process improvement

\subsection{Cluster of Performance Measurement Systems}

This cluster is constituted by the main organisational performance elements: Strategic objectives and associated KPIs. Initially, it will be possible to use any type of PMS as long as it assures a clear level of traceability between strategic objectives and KPIs. It is needed to have a balanced approach, in other words, not only focus on a specific organisational (financial one usually) but also on other important ones such as processes or customers. From a 
Balanced Scorecard point of view the main organisational performance elements will be the strategic objectives defined within the four balanced perspectives: Finance, Customers, Internal Processes and Learning \& Growth.

\subsection{Cluster of Outputs}

This cluster is constituted by the main outputs that will be created not only with the design and implementation of LP techniques but also through the achievement of the organisation's strategic objectives. The main expected outputs in this context are:

- Costs reduction

- Quality assurance

- Customer satisfaction

\subsection{Cluster of Stakeholders' Needs}

This cluster is constituted by the main stakeholders' needs and these will be gathered for each specific organisational competitive environment when applying this approach to a specific industry/service organisation.

\subsection{Next step: Pairwise Comparisons Between Elements}

As pointed out before, once both the decisional network and the relationships between the clusters have been defined, it is time to state the relative importance of a variable respect to another in order to reach a third one. This is done by a group of experts who have both the necessary knowledge and experience to emit sound judgement. Then, a Likert scale is used to assess such relative importance between variables. For instance, a question could be: How important is the LP technique SMED compared to the LP technique of JIT when aiming to achieve the strategic objective of "improving the customer loyalty level"?

These pairwise comparisons constitute the next phase of the ANP.

\section{Conclusions and Future Research Work}

This paper has set out a research question: To what extent the implementation of LP techniques affects to organisational performance. Due to the proliferation of LP techniques in both industrial and service companies in the last 40 years, it is necessary to identify and quantify how the investment of such techniques is paying off in terms of achieving organisational performance, not only at the operative and tactic levels but also at the strategic one.

Looking at the academic literature there are not works that have fully met and solved this research question. This paper suggests the usage of the Analytic Network Process as the tool to effectively link the implementation of LP techniques and organisational performance. Then, it has defined four clusters (Inputs, Performance Measurement Systems, Outputs and Stakeholders' Needs) and their relationships (inter and intra-clusters) in order to constitute a decisional ANP-based network to measure the impact of LP on organisational performance.

The design of such an ANP-based network is the first phase of the application of the ANP. Future research works should customise both the Performance Measurement System cluster (with the specific strategic objectives) and the Stakeholders' Needs cluster and then develop the other ANP phases for being able to establish the link between the implementation of LP and organisational performance.

\section{Declaration of Conflicting Interests}

The authors declared no potential conflicts of interest with respect to the research, authorship, and/or publication of this article.

\section{Funding}

The authors received no financial support for the research, authorship, and/or publication of this article. 


\section{References}

Aragonés-Beltrán, P., García-Melón, M., \& Montesinos-Varela, J. (2017). How to assess stakeholders' influence in project management? A proposal based on the Analytic Network Process. International Journal of Project Management, 35(3), 451-462. https://doi.org/10.1016/j.ijproman.2017.01.001

Asadabadi, M.J. (2017). A customer based supplier selection process that combines quality function deployment, the analytic network process and a Markov chain. European Journal of Operational Research, 263(3), 1049-1062. https://doi.org/10.1016/j.ejor.2017.06.006

Bashin, S. (2012). Performance of Lean in large organisations. Journal of Manufacturing Systems, 31(3), 349-357. https://doi.org/10.1016/j.jmsy.2012.04.002

Boj, J.J., Rodriguez-Rodriguez, R., \& Alfaro-Saiz, J.J. (2014). An ANP-multi-criteria-based methodology to link intangible assets and organizational performance in a Balanced Scorecard context. Decision Support Systems, 68, 98-110. https://doi.org/10.1016/j.dss.2014.10.002

Govindan, K., Azevedo, S.G., Carvalho, H., \& Cruz-Machado, V. (2015). Lean, green and resilient practices influence on supply chain performance: interpretive structural modelling approach. Int. J. Environ. Sci. Technol, 12, 15-34. https://doi.org/10.1007/s13762-013-0409-7

Kaplan, R., \& Norton, D. (1992). The balanced scorecard-measures that drive performance. Harvard Business Review, 70(1), 71-79.

Lee, C., \& Yang, H. (2011). Organization structure, competition and performance measurement systems and their joint effects on performance. Management Accounting Research, 22, 84-104. https://doi.org/10.1016/j.mar.2010.10.003

Lee, S., Park, S.B., \& Lim, G.G. (2013). Using balanced scorecards for the evaluation of "Software-as-a-service". Information \& Management, 50(7), 553-561.

Lynch, R., \& Cross, K. (1991). Measure Up-The Essential Guide to Measuring Business Performance. Mandarin, London.

Neely, A., Adams, C., \& Kennerley, M. (2002). The Performance Prism: The Scorecard for Measuring and Managing Business Success. London: Financial Times Prentice Hall.

Saaty, T.L. (1996) The analytic network process: decision making with dependence and feedback. Pittsburgh, PA: RWS Publications.

Seyedhosseini, S.M., Taleghani, A., Bakhsha, A., \& Partovi, S. (2011). Extracting leanness criteria by employing the concept of Balanced Scorecard. Expert Systems with Applications, 38(8), 10454-10461.

https://doi.org/10.1016/j.eswa.2011.02.095

Verdecho, M.J., Alfaro-Saiz, J.J., Rodriguez-Rodriguez, R., \& Ortiz-Bas, A. (2012). A multi-criteria approach for managing inter-enterprise collaborative relationships. Omega, 40(3), 249-263.

https://doi.org/10.1016/j.omega.2011.07.004

Journal of Industrial Engineering and Management, 2018 (www.jiem.org)

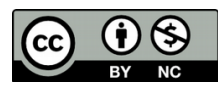

Article's contents are provided on an Attribution-Non Commercial 4.0 Creative commons International License. Readers are allowed to copy, distribute and communicate article's contents, provided the author's and Journal of Industrial Engineering and Management's names are included. It must not be used for commercial purposes. To see the complete license contents, please visit https://creativecommons.org/licenses/by-nc/4.0/. 